OS ESRAVC
DA MISERICÓ 


\section{OS ESCRAVOS DA MISERICÓRDIA}

\section{MÁR C I O C O U T O H E N R I QU E}

UNIVERSIDADE FEDERAL do PARÁ e INSTITUTO HistóRICO E GEOGRÁFICO DO PARÁ, BRASIL 


\title{
OS ESCRAVOS DA MISERICÓRDIA
}

\section{Resumo}

Este artigo analisa a relação da Santa Casa de Misericórdia do Pará com seus próprios escravos, ao longo do século XIX. Com base na documentação produzida pelos presidentes da província do Pará e nos relatórios dos provedores da Santa Casa, faz-se um apanhado histórico do tratamento dispensado aos escravos, os tipos de trabalhos em que eles eram usados e em que condições, a importância do trabalho escravo enquanto fonte de renda para a instituição, o papel dos escravos durante as epidemias, as doenças que os acometiam e as formas de tratamento. A pesquisa mostra que, se muitas vezes puderam fazer uso dos serviços médicos da instituição, não seria em irmandades como a Santa Casa de Misericórdia que os escravos encontrariam espaço para expressar suas angústias diante das tensões da escravidão.

Palavras-chave: Santa Casa de Misericórdia do Pará, hospital, escravidão.

\section{THE SLAVES OF MERCY}

\begin{abstract}
This article analyzes the relationship of the Holly House of Mercy of Pará with their own slaves, along the 19th century. Based on documents produced by the presidents of the Province of Pará and the Holly House providers' reports, the article presents a historical account of the treatment dispensed to the slaves, the tasks were asked to perform, the conditions provided for such tasks, the importance of the slave work force as a source of income for the institution, the slaves' role during times of epidemics diseases, the diseases they were subjected to and the treatment they received. The research shows that, if eventually they used the institution medical services, it wouldn't be in hospitals as Holly House of Mercy that the slaves would find support to express their distress under the pressures of servitude.
\end{abstract}

Keywords: Holly House of Mercy of Pará, hospital, slavery.

\section{LOS ESCLAVOS DE LA MISERICORDIA}

\section{Resumen}

En este artículo se analiza la relación de la Santa Casa de Misericordia de Pará con sus propios esclavos, durante el siglo XIX. En base a la documentación presentada por los presidentes de la provincia de Pará y de los informes de los proveedores de la Santa Casa, se ofrece un histórico del tratamiento a los esclavos, los tipos de puestos de trabajo en el que se utilizavan y en qué condiciones, la importancia del trabajo esclavo como fuente de ingresos para la institución, el papel de los esclavos durante las 
epidemias, las enfermedades que los afligian y las formas de tratamiento. La investigación muestra que, aunque a menudo pueden hacer uso de los servicios médicos de la institución, no sería en hospitales como la Santa Casa de Misericordia que los esclavos iban a encontrar espacio para expresar su angustia por las cepas de la esclavitud.

Palabras clave: Santa Casa de Misericordia de Pará, hospital, esclavitud.

Endereço do autor para correspondência: Faculdade de História da UFPA, Av. Augusto Correa no 01, bairro: Guamá CEP 66075-110, Belém, Pará. E-mail: marciocouto@ufpa.br 


\section{OS "HOMENS ABONADOS" E OS "DESVALIDOS DA SORTE"}

Muito embora vários estudos tenham apontado para a presença do negro na Amazônia (Salles 1988; VergolinoHenry \& Figueiredo 1990; Bezerra-Neto 2001), a singularidade da experiência escrava na irmandade da Santa Casa de Misericórdia do Pará (SCMP) ainda é tema não explorado em profundidade. Ampla documentação composta por relatórios, mensagens e falas dos presidentes da Província do Grão-Pará no século XIX constitui fonte preciosa para o estudo da experiência escrava na Amazônia, bem como para estudo ligado ao campo da história das instituições, principalmente em se tratando de instituição presente na história do Pará desde 1650. Lembre-se que Belém foi fundada em 1616, apenas 34 anos antes da fundação da irmandade da misericórdia. Desde suas origens, tratava-se de associação voltada para o serviço de caridade junto aos doentes, pobres, órfãos e prisioneiros. O termo "misericórdia", portanto, é utilizado no sentido de caridade, de serviço prestado aos mais necessitados.

Vicente Salles já havia observado que "entre as instituições possuidoras de escravos merece destaque a Santa Casa de Misericórdia do Pará" (1988: 178). A julgar por determinados artigos do Compromisso da SCMP, ${ }^{1}$ poder-seia inferir, anacronicamente, que por se tratar de associação religiosa, voltada para a assistência médica e espiritual aos "desvalidos da sorte", a irmandade dispensaria tratamento mais generoso aos seus próprios escravos. O Compromisso aprovado em 1854, por exemplo, dizia que "os fins da irmandade consistem na prática de obras pias e de misericórdia em favor e socorro dos pobres e dos enfermos desvalidos". 2 Mas leitura mais atenta destes estatutos mostra que não seria em irmandades como a Santa Casa de Misericórdia que os escravos encontrariam espaço para expressar suas angústias diante das tensões da escravidão.

Em primeiro lugar, os escravos não participavam da Santa Casa como confreiros, ou seja, como membros associados, haja vista que o estatuto desta irmandade proibia tal participação. A proibição se dava desde o primeiro Compromisso adotado pela SCMP (1650), e que tinha como base o da Santa Casa de Lisboa, de 1618, que exigia que seus membros não apresentassem "impureza de sangue pela mescla com judeu ou mouro", que soubessem ler e escrever e possuíssem bens (Vianna 1992: 10). Evidentemente, esses critérios excluíam os escravos, tanto pelo desconhecimento da leitura e da escrita, como por não "dispor de meios de segura subsistência” e serem estigmatizados pelo sangue considerado "infecto". Segundo Charles Boxer, para ser sócio da Santa Casa era necessário "ter situação suficientemente confortável para impedir qualquer tentativa de desviar fundos da Misericórdia, e servi-la sem que isso the causasse nenhum embaraço financeiro" (2002: 300).

Com relação à proporção de alfabetizados entre os escravos no Brasil, Eduardo Silva (1989:15) observa que, em 1872, por exemplo, menos de um a cada mil escravos sabia ler e escrever. 
Vicente Salles, por sua vez, em "O negro no Pará” (1988:146-7), afirma que "para os escravos era taxativamente vedada a educação". No Liceu Paraense, fundado em 1841, único estabelecimento público de instrução secundária da Província ao longo da segunda metade do século XIX, a matrícula era proibida aos que tinham moléstias contagiosas e aos que não eram livres.

Como em outras partes do Brasil, a irmandade da SCMP reunia em seus quadros elementos da elite econômica e intelectual paraense. Em 1891, constavam na "Lista dos sócios da Santa Casa de Misericórdia" 310 nomes. Dentre eles, havia 30 doutores, 20 bacharéis, cinco tenentes-coronéis, cinco engenheiros, quatro majores, três comendadores, três cônegos, dois conselheiros, dois coronéis, um capitão, um desembargador e um padre-Dr. Diversos sócios da SCMP ocuparam os cargos de deputado estadual, presidente da província ou governador (a partir da República). Dentre os mais conhecidos, citam-se Antonio Lemos (eleito intendente de Belém, equivalente a prefeito municipal, em 1897), Antonio Nicolau de Monteiro Baena (senador entre 1890-1897, vice-governador entre 1897-1898), Justo Leite Chermont (1857-1926, deputado provincial, governador do Pará, ministro e senador), Augusto Montenegro (governador do Pará), barão de Guajará (Domingos Antonio Raiol, 1830-1912, foi presidente das províncias de Alagoas, Ceará e São Paulo) e Francisco da Silva Castro (1837-1899, médico). ${ }^{4}$ Conforme Charles Boxer, "o cargo de provedor era muito valorizado devido ao elevado status social que proporcionava ao ocupante, embora pudesse levar um homem consciencioso a ficar extremamente endividado" (2002: 302). Nem todos os nomes acima citados ocuparam a função de provedor, mas sua presença na condição de sócios serve de indicativo do prestígio social alcançado pela SCMP.

Em 1849, o patrimônio da SCMP compreendia o templo de Santo Alexandre, o "hospício" dos lázaros na fazenda Tucunduba, o Hospital Bom Jesus dos Pobres, quatro fazendas: Pinheiro (atual Icoaraci), Graciosa (no rio Capim), Caviana (na foz do Amazonas) e Bom Jesus (no Marajó), um cacoal no rio Capim, 31 casas de aluguel e 162 escravos (Vianna 1992). Estes últimos eram utilizados em fazendas de criação de gado, na indústria extrativa, no trabalho de lavoura e em profissões tais como pedreiros, carpinteiros, ferreiros, calafates, enfermeiros, cozinheiros e serventes do cemitério. Nos episódios narrados a seguir, pode-se ter ideia do tratamento que a irmandade dispensava a estes "desvalidos da sorte".

Em 25 de setembro de 1839, conforme Arthur Vianna (1992), estiveram presentes à reunião da mesa administrativa da Santa Casa "três míseras pretas" que haviam fugido da fazenda do Capim. Tendo os mesários discutido a punição que deveria ser imputada a elas, decidiram por unanimidade de votos que cada uma deveria receber seis dúzias de palmatoadas dentro do Hospital do Bom Jesus dos Pobres, em Belém, onde se achavam reunidos, no 
Largo da Sé. ${ }^{5}$ Se, por um lado, o fato das três "míseras pretas" terem fugido da fazenda da SCMP pode servir de indicativo de tratamento que não lhes agradava, as seis dúzias de palmatoadas não deixam dúvida quanto ao recurso à violência enquanto estratégia de controle por parte da administração da irmandade.

Não foi diferente a "sorte" de Felippe e Lázaro, também escravos da Santa Casa, que haviam fugido do Pinheiro e foram presos em Belém. A mesa administrativa (1843-1844), com o consentimento do chefe de polícia, ordenou que fossem dados nos dois "seiscentos açoites". Felippe chegou a receber o "bárbaro castigo" como denominou Arthur Vianna, "porém o seu infeliz companheiro antecipou a tarefa dos carrascos garroteando-se em uma árvore" (1992:145). Fica evidente que o fato de Felippe e Lázaro e as "três míseras pretas" serem escravos de uma irmandade, ou seja, de associação religiosa voltada para fins de caridade, de serviço aos pobres, não os torna isentos da violência do controle senhorial.

Se Arthur Vianna apresenta sem embaraço o tratamento que a SCMP dispensava aos escravos, nota-se que ao escrever sobre a instituição em outras partes do Brasil, alguns autores evidenciam certo desconforto ao tratar do mesmo tema. É assim que, ao tratar da escravidão na Santa Casa de Misericórdia do Rio de Janeiro, Dahas Chade Zarur afirma que

"nunca existiu a escravatura na Irmandade da Misericórdia, embora tivesse cativos, porém, quando prestavam serviços à Instituição, recebiam um ordenado. Todos tinham ocupação, um salário, com roupa, alimentação, remédios e eram livres" (1981: 23)

$\mathrm{O}$ autor resolve o que parece ser um desconforto em assumir a existência da escravidão numa instituição que ele define como "fonte de luz, caridade e justiça" acomodando de forma bastante confusa e anacrônica trabalhadores que são, ao mesmo tempo, "cativos" que prestam serviço à Santa Casa e "livres" assalariados. Postura bem diferente é adotada por Vianna, ao se referir à relação da irmandade paraense com a escravidão:

"A Misericórdia desde longa data possuía escravos, em não pequeno número, nem lhe era permitido prescindir d'elles quando dos seus braços sahiam exclusivamente os serviços de criadagem, da industria extractiva e pastoril, do amanho das terras de lavoura, das artes manufactureiras; ela os comprou, vendeu, permutou e empregou como qualquer capitalista, sem ter por elles mais compaixão do que os outros, sem ver nelles outra cousa que não o emprego do capital, cujos juros auferia" (1992: 145)

Nascido em 1873, Arthur Vianna ainda conviveu com a escravidão, tendo 15 anos de idade por ocasião da Abolição. Além dos fatos que guardou em sua memória, ele teve acesso a ampla e variada documentação, na qual pôde visualizar a relação da Santa Casa de Misericórdia do Pará com seus escravos. 


\section{A CABANAGEM E O (DES)CONTROLE DOS ESCRAVOS}

A SCMP não passou incólume aos acontecimentos da Cabanagem. Até 14 de agosto de 1835, os negócios da instituição estiveram a cargo de Sebastião José da Silva, nomeado por Felix Antonio Clemente Malcher, primeiro presidente cabano, definido por Arthur Vianna como "presidente intruso" (1992:135). Da referida data até a retomada de Belém pelas forças legalistas $(13 / 05 / 1836)$, a provedoria foi ocupada pelo enfermeiro Carlos dos Reis Magos, que voluntariamente assumiu o cargo. No Hospital do Senhor Bom Jesus dos Pobres, os rebeldes cabanos levantaram uma trincheira guarnecida com canhão de pequeno calibre. Ao avaliar as "peripécias da revolução e as suas consequências" para os negócios da SCMP, Vianna afirma que "os escravos em sua maioria tinham-se aproveitado do cataclysma, fazendo causa comum com os cabanos ou fugindo para quilombos ou sítios ignorados" (1992:137). Como indicativo do aspecto polissêmico da Cabanagem, note-se que muitos destes escravos lutaram lado a lado com membros da diretoria da Santa Casa, tais como o provedor Ignacio José Pestana, que apoiou a aclamação de Malcher, sendo morto ao longo do conflito.

Durante a Cabanagem, as fazendas da SCMP tornaram-se alvo fácil de saqueadores. Ao descrever os bens da fazenda Caviana (na foz do Amazonas), em 1838, o presidente da província, Soares Andréa, afirmou que "nesta fazenda existem 35 escravos da Casa, e nada tem produzido depois da Revolução" (Pará 1838: 38). Na mesma data, a fazenda Graciosa (também chamada de Caridade), no Rio Capim, tinha 99 escravos, mas somente 35 destes eram "de serviço" (Pará 1838: 38). Na fazenda Bom Jesus, de gado vacum e cavalar, na ilha do Marajó, restou apenas "um escravo velho" (Pará 1838:18). Crítico dos "mais cannibaes attentados contra a propriedade particular" e defensor da legalidade que veio "restabelecer a paz", Vianna observava que "por toda a parte o rasto vermelho da lucta fratrecida deixára manchas indeleveis" (1992:137).

Uma das principais tarefas a que se dedicou a SCMP depois da retomada de Belém pelas forças legalistas foi exatamente a de readquirir seus escravos. Muitos escravos de ganho estavam dispersos pelas casas de seus alugadores e a Irmandade teve de recorrer à presidência da província para "arrancar as suas alimarias humanas das mãos dos que gozavam-lhe os serviços braçais" (Vianna 1992:145).

Em 1844, o presidente da província, Manoel Paranhos da Silva Vellozo, parabenizava o provedor da SCMP, João Baptista de Figueiredo Tenreiro, pelos melhoramentos que vinha fazendo nos negócios da instituição

“... tratando do concerto e bemfeitorias do seu Templo, Hospital, e de vinte e duas propriedades, do aproveitamento de suas Fazendas, que estavam em abandono, e em ruína, e no aumento de seus rendimentos, concorrendo assim eficazmente para que este Pio 
estabelecimento vá surgindo do estado decadente a que o levou a crise devastadora porque passou a Província, deixando-o reduzido aos únicos rendimentos de uma Fazenda e de alguns prédios e escravos artistas com que teve de ir socorrendo os enfermos no seu hospital e os infelizes Lázaros" (Pará 1844: 26).

À essa época a fazenda Graciosa possuía 90 escravos, nove a menos do que em 1838, sendo que a maior parte era formada por velhos, mulheres e crianças. Talvez por isso o presidente da província tenha lamentado que a referida fazenda "produz um muito tênue rendimento com que são mantidos os escravos que ali existem, os quais pelas suas circunstâncias pouco serviço prestam" (Pará 1844: 27). Com relação à fazenda do Pinheiro, dizia o presidente da província que, quando passou ao domínio da Santa Casa, estava "em ruína, e os escravos tinham perdido o hábito do trabalho, não chegando os rendimentos para sua manutenção" (Pará 1844: 27). De certa forma, esta desestruturação parece ter significado certa flexibilidade no controle senhorial, pois os escravos da fazenda Caviana nada produziam depois da "Revolução" e os da fazenda Pinheiro "tinham perdido o hábito do trabalho" e mal produziam para seu próprio sustento.

As fugas dos escravos da Santa Casa eram anunciadas nos jornais de Belém, como a que foi publicada em $\mathrm{O}$ Planeta, aos 17 de agosto de 1850:

"Fugiram no corrente ano os seguintes escravos da Santa Casa de
Misericórdia - Januário, preto, baixo, barrigudo, de 48 anos de idade, pouco mais ou menos, suspeitando-se andar para o distrito do Rio Capim - Izidoro, preto, baixo, 30 anos pouco mais ou menos, - Jesuíno, preto fulo, estatura regular, carapinha um pouco branca, voz grossa, de idade de 50 a 60 anos; suspeita-se estar na Ilha Caviana: quem os capturar e os entregar nesta cidade ao mordomo dos escravos Paulo Maria Perdigão, ou ao Provedor Joaquim António Alves, será recompensado convenientemente" (Salles 1988:324)

Tanto no rio Capim quanto na região do Marajó, onde ficava a fazenda Caviana, havia quilombos que acolhiam escravos fugidos, conforme mostra mapa elaborado por Vicente Salles (1988: 219). Em abril de 1851, Manoel Gonçalves do Rêgo, morador de São Caetano, anunciava no periódico "O Planeta" a fuga de dois de seus escravos, acrescentando: "consta-lhe estarem pelo distrito de Chaves em Marajó, na fazenda da Santa Casa, acoutados por um prêto de nome Ponciano" (Salles 1988: 215). Este dado é importante na medida em que evidencia a articulação e solidariedade entre companheiros de infortúnio, bem como a atitude audaciosa dos escravos da SCMP ao darem couto aos fujões, mesmo sabendo do rigor das penalidades que incidiam sobre esta prática. Os anúncios de fuga de escravos geralmente terminavam com expressões do tipo "protestando-se contra o acoutamento ou quem tiver parte em sua fuga", "protesta-se contra quem o ocultar" ou "protesta-se com todo o rigor da lei contra quem 
lhes der couto (op. cit: 318-325).

$\mathrm{O}$ fato das fazendas ficarem muito distantes de Belém e o suposto "desleixo dos administradores" dificultava maior controle dos escravos. Pelo menos é o que diz o presidente da província Fausto Augusto de Aguiar em seu relatório de 1852:

"À exceção da do Pinheiro, todas essas fazendas estão a longas distâncias desta capital e, em tais circunstâncias, torna-se impraticável exercer sobre elas uma inspeção eficaz; ao que acresce terem habituado os escravos, que nelas existem, a uma vida de inércia, da qual sem muita energia e perseverança não é possível arrancá-los" (Pará 1852: 80)

A proximidade entre a fazenda do Pinheiro e a capital paraense tornava o controle dos escravos mais eficaz, o que pode ter sido determinante na fracassada tentativa de fuga de Felippe e Lázaro, conforme vimos mais acima. Pesquisa mais aprofundada poderia demonstrar se os escravos que trabalhavam nas fazendas da SCMP estavam realmente mergulhados numa vida de "inércia" ou se simplesmente aproveitavam a ausência de controle efetivo para se dedicar a outras tarefas, prestando serviços para outros fazendeiros da região ou estabelecendo comércio com regatões, por exemplo. Segundo Vianna, uma inspeção realizada pela administração da SCMP na fazenda Bom Jesus, pouco depois da Cabanagem, revelou "que o feitor Francisco, escravo da Misericórdia, passava todo o tempo na fazenda do commendador Seixas, a quem servia voluntariamente, deixando à revelia os serviços de que estava incumbido" (1992:145). De todo modo, as constantes queixas dos provedores com relação à baixa produtividade ou à "inércia" dos escravos da Misericórdia evidenciam atitudes explícitas de enfrentamento por parte dos escravos.

\section{OS ESCRAVOS E SEUS OFÍCIOS}

Se os escravos empregados nas fazendas eram motivo de descontentamento, os escravos "artistas" constituíram importante fonte de renda para a SCMP. Em 1845, o presidente da província dizia que "de sua escravatura parte está empregada no serviço das Fazendas, e Hospitais e parte são artistas e aprendizes de ofícios" (Pará 1845:43). Vimos mais acima que no pós-Cabanagem, além de uma fazenda e de alguns prédios a SCMP ficou reduzida a alguns escravos artistas com que teve de ir socorrendo os enfermos no seu hospital e os Lázaros do Tucunduba.

O presidente da província Francisco Carlos de Araújo Brusque, em seu relatório de 1861, informou que nesta data a SCMP possuía 125 escravos, avaliados em 62:100\$000. Brusque observou que "desta relação dos bens patrimoniais é fácil concluir que, entre eles figuram, em primeiro lugar e com maior valor, os escravos que infelizmente são os que oferecem menor garantia, por isso que sua existência é a mais precária” (Pará 1861:17). Os 125 escravos da SCMP valiam mais do que os 29 prédios que a instituição alugava para terceiros em Belém, avaliados 
em 50:000\$000. Dos 125 escravos, 15 pagavam jornal, 20 estavam alugados e cinco fugidos. Em 1863, as receitas provenientes de jornais de escravos alcançaram a cifra de 3:637\$180, constituindo a maior fonte de receita da instituição (Pará 1863:18). Neste ano, 28 escravos eram classificados na condição de "ganhador", sendo todas mulheres entre cinco e 51 anos (op. cit. anexo 4).

Muitos escravos da Santa Casa utilizaram o pecúlio acumulado em anos de trabalho "de ganho" para comprar sua carta de alforria, como os dez que foram manumitidos em 1868 (SCM 1868:12). O fato de escravos de "existência precária" constituírem o principal patrimônio da SCMP preocupava o presidente da província. Em 1862, Araújo Brusque novamente observava que "os escravos estão sujeitos a tantas eventualidades que o capital que representam é muito precário" (Pará 1862:73).

O relatório da provedoria da SCMP referente ao ano de 1867 apresenta a "Relação nominal dos escravos pertencentes à Santa Casa da Misericórdia do Pará” (SCM 1868: 8-9), na qual é possível ver em detalhes quais as ocupações dos 92 escravos que a irmandade possuía àquela data. No quadro 1, constam aqueles que aparecem na "Relação" associados a algum tipo de atividade ou "ofício" que implicasse em lucro para a SCMP.

Note-se que, dentre os 92 escravos da SCMP em 1867, havia seis pedreiros, quatro carapinas (ou carpinteiros), dois ferreiros, um calafate, seis serventes do cemitério (um deles era carapina), quatro trabalhavam no hospital e três eram aprendizes de pedreiro. Note-se ainda que a especialização dos escravos estava relacionada a atividades altamente valorizadas à época, enquanto possibilidade de obtenção de lucros com a mão-de-obra escrava. Dos 13 escravos com "ofício", 12 trabalhavam na capital, Belém. Mas, possivelmente, o escravo carapina Américo também era da capital posto que, segundo a observação do escrivão Francisco Breton Ferreira Monforte, Américo estava "na fazenda Graciosa, em correção por ser vicioso". Diz Salles que "nas cidades (Belém e São Luís) havia artesãos livres, mas a grande maioria era mesmo composta de escravos: propriedade ou de um mestre europeu ou de senhores necessitados de especialistas para suas fazendas e engenhos, que os entregavam, crianças ainda, a um mestre artesão a fim de formá-los oficiais" (1988:161)

Considerando os escravos aprendizes na capital, além dos três escravos serem aprendizes do mesmo ofício, pedreiro, chama atenção a idade dos aprendizes: Ovídio, o mais novo, tem apenas oito anos. Já Alfredo, o mais jovem dos aprendizes, tem 12 anos, a mesma idade do pedreiro Manoel, que já prestava serviços na capital na condição de pedreiro especializado. Mas na "Relação nominal dos escravos pertencentes à Santa Casa da Misericórdia do Pará em setembro de 1863", o nome de Alfredo já consta como aprendiz, com sete anos de idade (SCM 1863).

Entre os escravos de ofício mais velhos, Felippe, Marcelo e Fernando têm 48 anos, o que pode ser indicativo $\mathrm{da}$ quantidade de anos que estes escravos suportavam em tais condições, 
Quadro 1

Escravos da Santa Casa da Misericórdia do Pará e seus “ofícios” em 1867

\begin{tabular}{|c|c|c|c|}
\hline NOME & IDADE & OFÍCIOS & OBSERVAÇÕES \\
\hline \multicolumn{4}{|c|}{ ESCRAVOS COM “OFÍCIO” } \\
\hline Américo & 46 & Carapina & $\begin{array}{l}\text { Na fazenda Graciosa, em correção } \\
\text { por ser vicioso }\end{array}$ \\
\hline Porfírio & 23 & Carapina & Na capital \\
\hline Innocêncio & 19 & Carapina & Na capital \\
\hline Felippe & 48 & Pedreiro & Na capital \\
\hline Marcelo & 48 & Pedreiro & Na capital \\
\hline Marcos & 26 & Pedreiro & Na capital \\
\hline Manoel & 12 & Pedreiro & Na capital \\
\hline Prisco Antonio & 19 & Pedreiro & Na capital \\
\hline Victório Antonio & 36 & Pedreiro & Na capital \\
\hline Aniceto Antonio & 30 & Ferreiro & Na capital \\
\hline Fernando & 48 & Ferreiro & Na capital \\
\hline Laurianno & 35 & Calafate & Na capital \\
\hline \multicolumn{4}{|c|}{ ESCRAVOS APRENDIZES } \\
\hline Alfredo & 12 & & Na capital, aprendendo a pedreiro \\
\hline Arnaldo & 10 & & Na capital, aprendendo a pedreiro \\
\hline Ovídio & 8 & & Na capital, aprendendo a pedreiro \\
\hline \multicolumn{4}{|c|}{ ESCRAVOS SERVENTES DO CEMITÉRIO } \\
\hline Bento Antonio & 23 & & Servente do cemitério \\
\hline Domingos Barbosa & 23 & & Servente do cemitério \\
\hline Ezequiel & 28 & & Servente do cemitério \\
\hline Hortêncio Antonio & 40 & Carapina & Servente do cemitério \\
\hline Mamede & 22 & & Servente do cemitério \\
\hline Pedro & 35 & & Servente do cemitério \\
\hline \multicolumn{4}{|c|}{ ESCRAVOS SERVENTES DO HOSPITAL } \\
\hline Clarindo & 19 & & Servente do hospital \\
\hline Porcino da Cruz & 23 & & Servente do hospital \\
\hline Joanna Baptista & 60 & & Cozinheira do hospital \\
\hline Raymundo Theodoro & 43 & & Enfermeiro do hospital \\
\hline
\end{tabular}


expostos a trabalhos pesados a partir dos sete anos. De um modo geral, os mapas elaborados pelos provedores indicam que poucos escravos da SCMP passavam dos 60 anos. Em 1868, dos 92 escravos, apenas oito deles tinha 60 anos ou mais. Em todo caso, destes oito, três tinham 74 anos, sendo duas mulheres e um homem. Talvez as mulheres estivessem envolvidas em atividades menos desgastantes fisicamente. A escrava Joanna Baptista, por exemplo, aos 60 anos de idade era cozinheira do hospital Bom Jesus dos Pobres, onde muito provavelmente desempenhava funções menos desgastantes do que as mulheres que estavam empregadas nas roças. Em todo caso, Antonio Lourenço, o escravo que aparece na relação de 1868 com 74 anos, sem indicação de ofício, é uma exceção, pois na relação de 1863 ele consta como pedreiro, muito embora seja definido como "inválido". Seis dos escravos com 60 anos ou mais viviam na fazenda Graciosa, espaço que servia de "retiro para os velhos, aposentados ou reformados, que vão lá para buscar descanso" (SCM 1863:12). Ao registrar uma observação ao lado do nome do escravo Américo, carapina de 46 anos, o escrivão Francisco Breton Ferreira Monforte revelou uma função estratégica da fazenda Graciosa. Afinal, Américo estava lá "em correção por ser vicioso".

O fato de que em 1867 a SCMP ainda funcionava no Hospital Bom Jesus dos Pobres, no largo da Sé, de frente para a baía do Guajará, explica a especialidade do escravo Laurianno, calafate. Conforme Salles, "um dos ofícios mais di- fundidos, tanto entre escravos negros como gentios, foi o de calafate, importante para a conservação das embarcações fluviais" (1988:165). Mais do que nunca, os rios da Amazônia àquela época funcionavam como ruas e muitos doentes chegavam ao hospital da Santa Casa por via fluvial, em pequenas embarcações, às vezes pertencentes à própria Santa Casa. Calafates, pedreiros, carpinteiros e ferreiros poderiam ser utilizados tanto em serviços na instituição quanto poderiam ser alugados ou prestarem serviços a terceiros. Eram, portanto, os escravos mais valorizados, alcançando a avaliação de cada um a cifra de 1:000\$000, enquanto os escravos que trabalhavam na roça, por exemplo, raramente ultrapassavam a avaliação de $800 \$ 000$ (Pará 1863: anexo 4).

Com relação aos escravos que eram serventes no hospital, as queixas eram constantes. Matéria publicada no periódico "Publicador Paraense", aos 11 de março de 1850, criticava o atendimento dispensado aos marinheiros enfermos:

\begin{abstract}
"Que importa porém tanto desvelo da parte do zeloso facultativo (Dr. Malcher), se na sua ausência tudo ali fica entregue às moscas! E apenas lá quando muito lhe parece é que o negro servente sujo e estúpido, anima a cabeceira do infeliz a melancólica dieta, e tarde e às más horas entorna na própria vasilha dela a nauseabunda mesinha para ser tomada pela mórbida mão do nauta sem sentidos! E sem socorro!!...” (Salles 1988:179-180)
\end{abstract}

Em 1868, o escrivão da SCMP, Francisco 
Breton Ferreira Monforte, reclamava que "o serviço de enfermeiro e serventes das enfermarias é feito por escravos da Santa Casa, e por isso mesmo é muito irregular, porque além desses escravos serem viciosos, fazem o serviço de muito má vontade, e lembro-vos que fosse esse serviço feito por homens livres e mais caritativos para com os enfermos" (SCM 1868: 2)

$\mathrm{Na}$ mesma data, uma enfermeira branca e livre trabalhava no hospital da Santa Casa recebendo mensalmente $6 \$ 000$, o que pode ajudar a entender a "má vontade" com que os escravos desempenhavam a mesma função sem nada receber. Além do transtorno de serem obrigados a desempenhar trabalho para o qual não foram preparados, os escravos serventes do hospital da SCMP ainda tinham que conviver com o tratamento discriminatório daqueles que os consideravam sujos, estúpidos e viciosos. Em 1884, chegou a Belém o grupo das primeiras Irmãs Filhas de Sant'Ana, religiosas italianas que substituiriam os escravos no serviço do hospital. ${ }^{6}$

Note-se que seis escravos estavam na condição de "serventes do cemitério": Bento Antonio, Domingos Barbosa, Ezequiel, Hortêncio Antonio, Mamede e Pedro. Em 1785, a SCMP obteve da Coroa portuguesa o privilégio da condução dos cadáveres aos cemitérios. Com o passar dos anos, a irmandade descuidou deste privilégio, só vindo a recuperá-lo das mãos de particulares em 1851. Apenas as corporações religiosas tinham o direito de transportar em tumba especial os cadáveres de seus associados, sendo proibido o transporte dos corpos em rede, prática até então comum no enterro da gente pobre da região. Durante as epidemias de cholera-morbus, varíola e febre amarela, ocorridas no Pará no século XIX, os escravos da SCMP exerceram um papel decisivo. Eram eles que conduziam sobre seus ombros os cadáveres do hospital e das residências para o cemitério da Soledade, onde também faziam as vezes de coveiro. ${ }^{7}$ O Soledade foi construído em 1850, para o enterro dos acometidos por febre amarela.

Durante a epidemia de cholera-morbus (1855), quatro canoas tripuladas por escravos da Santa Casa serviam de transporte aos doentes que eram conduzidos ao hospital da Misericórdia (Vianna 1992: 205). Não é difícil imaginar que esta proximidade com os mortos, com a morte e com doenças infecciosas, sujeitava os escravos da SCMP que executavam estas funções a toda sorte de estigmatizações. Lembra Salles que "havia ofícios que, por seu caráter deprimente, apenas aos escravos era dado executar: coveiros, carregadores de excrementos humanos, carrascos, etc.” (1988:162).

Nos rituais de enforcamentos existentes no Pará até meados do século XIX, os escravos da SCMP também constituíam presença importante. Digo rituais porque, de fato, a prática dos enforcamentos seguia todo um conjunto de ritos, utilizados pelos poderes públicos para mostrar, por meio de um "exemplo salutar", a força de sua disciplina e moral (Cruz s/d:187). ${ }^{8}$ 
Antes da execução, ainda de madrugada, alguns escravos da Santa Casa examinavam as traves e as cordas da forca, muitas vezes armada no largo de São José (em frente ao atual Pólo Joalheiro) e no largo da Pólvora (na atual Praça da República). Também na madrugada, o homem do balandrau azul, membro da irmandade que tinha como função fazer os anúncios e convites da Santa Casa, percorria as ruas badalando sua campa e clamando aos devotos: "Orai pelo nosso Irmão padecente".

As palavras do homem do balandrau azul soavam como convite para um espetáculo. Era grande o movimento nas ruas no dia marcado para a execução. Segundo a descrição de Vianna, os escravos atribuíam significado próprio àquele momento:

"Era o meio de liberdade que gozavam (...) longe dos vergalhos e dos suplícios (...) todos dispensados a pretexto de verem no castigo infligido ao criminoso um exemplo salutar" (Vianna 1992: 247).

Em todo caso, para os escravos da SCMP o ritual de enforcamento não representava distância dos suplícios, pois era a eles que cabia a função de - vestidos de preto - carregar nos ombros "a grande tumba dos pobres, negro caixão abahulado, com enorme cruz branca sobre a tampa, que devia transportar o corpo do enforcado para a obscura sepultura" (Vianna 1992: 249).

Depois de celebrada missa, todos se dirigiam ao local do enforcamento, onde o escrivão lia a sentença e o carrasco dava fim ao sofrimento do padecente, ao som dos gritos, gargalhadas e gracejos da multidão que insistia em fazer da morte do outro uma festa (Reis 1991). Como este momento também era de disciplinarização, o ritual terminava com sermão proferido por um frade, que procurava aproveitar "aquela comovente tragédia para a predica moral" (Vianna 1992: 251). Só então a multidão se dispersava e os escravos da Santa Casa metiam o cadáver no caixão.

A partir da leitura dos relatórios dos provedores da Santa Casa, pode-se depreender que os escravos serventes do cemitério estavam sujeitos a péssimas condições de trabalho. Aos cinco de outubro de 1863, o provedor da SCMP, Dr. Francisco da Silva Castro, afirmava em seu relatório que "a condução dos cadáveres dos pobres e escravos, tem-se feito de janeiro em diante em um veículo funerário, apropriado, o qual representa a forma de uma catacumba. Com esta reforma muito tem lucrado a saúde dos escravos, serventes do Cemitério" (SCM 1863:10).

Apesar de não indicar claramente como era feito o transporte dos pobres e escravos mortos antes da adoção da catacumba, o Dr. Silva Castro reconhece que o sistema anterior era inapropriado e causava problemas à saúde dos escravos da SCMP que eram serventes do cemitério.

Quem esclarece o sistema anterior de condução dos cadáveres é Cândido do Prado Pinto, provedor interino, no relatório da SCMP datado de 30 de junho de 1868. O provedor interino faz referências à atitude de um viceprovedor que teria suspendido a con- 
dução dos cadáveres de pessoas pobres e escravos pelo carro funerário, substituindo-o pelo esquife. Cândido do Prado Pinto apenas diz que o viceprovedor teve "poderosas razões" para tomar esta atitude, mas é bem provável que o carro funerário estivesse sendo usado apenas para a condução dos cadáveres de pessoas de posses, enquanto os pobres e escravos eram conduzidos no esquife.

Ao justificar porque determinou o retorno do carro funerário, o provedor interino argumenta que a condução por meio do esquife era, além de penosa para os escravos, mais dispendiosa para a Santa Casa. Havia dias em que era necessário fazer quatro a cinco viagens de busca e condução de cadáveres, muitas vezes em pontos extremos da cidade de Belém e este serviço ocupava quatro escravos. Segundo o provedor, "bem se vê que um corpo, ainda que por melhor nutrido que seja, ressente-se com um serviço tão pesado e contínuo" (SCM 1868:3). Dificilmente este era o caso dos escravos empregados no cemitério, sujeitos a uma alimentação deficitária.

Muito embora demonstre certa preocupação com as condições de trabalho dos escravos, a maior parte dos argumentos do provedor estão relacionados ao caráter dispendioso da condução dos cadáveres por meio do esquife.

Quanto a ser dispendioso, a razão é fácil de compreender-se:

"são precisos quatro escravos vestidos ou fardados de preto para a condução do esquife, o que já não acontece com o do carro funerário em que são empregados dois escravos somente.

Acresce mais que para o serviço funerário é de rigorosa necessidade estarem pelo menos seis escravos empregados no cemitério para não haverem faltas nos enterramentos, já na abertura das sepulturas, já na condução dos cadáveres, o que se poderá evitar, sendo o serviço feito por meio do carro funerário em que se empregarão dois escravos e os mais em outros serviços." (SCM 1868:3)

O número de escravos utilizados em cada um dos modos de condução dos cadáveres foi determinante na decisão do provedor a favor do transporte no carro funerário. Mas mesmo os carros funerários utilizados pela SCMP eram alvos de críticas do provedor interino Cândido do Prado Pinto. Diz ele que:

"Tenho presenciado que o carro funerário que atualmente usa a Santa Casa, em vez de infundir respeito causa horror, e para que a povoação não repugne tanto essa espécie de condução dos cadáveres, lembro-vos mandar fazer um carro apropriado como os que se usa no Rio de Janeiro, Bahia e Pernambuco, onde a Santa Casa tem como renda avultada carros de $1^{\mathrm{a}}, 2^{\mathrm{a}}$ e $3^{\mathrm{a}}$ classes, encarregando-se a mesma dos enterramentos por um preço estipulado conforme as posses de cada um" (SCM 1868: 3)

Ao invés de destinar o carro funerário apenas para as pessoas de posses, o provedor preferia fazer carros apropriados, que não causassem horror à população, e que pudessem ser disponibilizados "conforme as posses de 
cada um". Desta forma, além de melhorar a imagem que a população tinha do carro funerário, haveria aumento nos lucros obtidos com o serviço. De fato, a partir de 1869 o transporte dos corpos passou a ser feito apenas em carros funerários, divididos em quatro "classes". Os indigentes, as recolhidas no colégio de Nossa Senhora do Amparo e os que falecessem nas enfermarias do Exército e da Armada teriam transporte gratuito. Como dito antes, não é difícil imaginar que os escravos da SCMP, responsáveis pela condução dos cadáveres, tivessem sua imagem pessoal associada ao esquife ou ao carro funerário que, ao invés de suscitarem respeito, causavam horror e repugnância.

\section{CAUSAS DE MORTE DOS ESCRAVOS DA SANTA CASA DE MISERICÓRDIA DO PARÁ}

Os relatórios dos provedores da Santa Casa de Misericórdia do Pará também nos revelam as causas de morte de al- guns escravos, conforme demonstra o quadro 2.

Lina e Clara morreram de "tubérculos pulmonares". A tuberculose pode afetar quase todos os tecidos ou órgãos do corpo, sendo mais comum nos pulmões. Os sintomas mais gerais são a sudorese (suor excessivo), febre e emagrecimento (Stedman 1996: 376).

Segundo o Dicionário de Medicina Popular, de Chernoviz, o "amolecimento do cérebro" é caracterizado "por um enfraquecimento gradual das faculdades intelectuais, da sensação, do movimento, pela diminuição da memória, dificuldade no falar, dores de cabeça, e, nos casos mais graves, pela paralisia geral"' (1878:158). Não sabemos a idade de Bruno, o escravo que morreu de "amolecimento cerebral", mas Chernoviz afirma que se trata de uma "moléstia própria da velhice, e excessivamente rara nas crianças" (op. cit: 159).

Eczema é um termo genérico utilizado em medicina para condições inflamatórias agudas ou crônicas da pele,

Quadro 2

Causas de mortes dos escravos da Santa Casa de Misericórdia do Pará

\begin{tabular}{|l|l|l|}
\hline \multicolumn{1}{|c|}{ NOME } & \multicolumn{1}{|c|}{ CAUSA DA MORTE } & \multicolumn{1}{c|}{ FONTE } \\
\hline Lina & Tubérculos pulmonares & SCM 1863:15 \\
\hline Clara & Tubérculos pulmonares & SCM 1863:15 \\
\hline Bruno & Amolecimento cerebral & SCM 1863:15 \\
\hline Justiniano (menor) & Eczema sifilítico & SCM 1863:15 \\
\hline Basília (menor) & Febre meningo gástrica & SCM 1863:15 \\
\hline Joaquim Caetano & Hepatite aguda & SCM 1863:15 \\
\hline Zeferino & Gastro hepatite aguda & SCM 1868: 14 \\
\hline Joaquim de Santana & Gastrite ligeira & SCM 1868: 14 \\
\hline Silvestre & Asfixia por submersão & SCM 1868: 14 \\
\hline
\end{tabular}


geralmente acompanhada por sensações de prurido e ardência (Stedman 1996: 404). No caso do "eczema sifilítico" que acometeu o escravo Justiniano, trata-se das manifestações dermatológicas da sífilis, doença muito comum no século XIX, a tal ponto de ser chamada de "o mal da virada do século" (Carrara 1996). Em se tratando de escravo menor de idade, é bem provável que Justiniano tenha adquirido sífilis de forma congênita (transmitida por sua mãe durante a gestação).

O escravo Joaquim Caetano morreu em consequência da "hepatite aguda", inflamação do fígado causada geralmente por infecção virótica, mas que também pode ser causada por agentes tóxicos (Stedman 1996:584). No caso de Zeferino, empregado na roça, que morreu com 57 anos, de "gastro hepatite aguda", trata-se de complicações que atingiram ao mesmo tempo o estômago e o fígado. Também morreu com problemas estomacais, aos 34 anos, o escravo Joaquim de Santana, empregado na roça. A gastrite é uma inflamação, especialmente da mucosa do estômago, que causa muitas dores (Stedman 1996:526).

Silvestre, calafate de 25 anos, morreu afogado, fato definido no relatório como "asfixia por submersão”. Segundo Chernoviz, "os afogados morrem de asfixia, isto é, da privação do ar atmosférico, que eles não podem respirar, por terem a cabeça debaixo d'água" (1878: 47). Sua morte deve ter representado enorme prejuízo para a SCMP, haja vista que se tratava de escravo jovem e especializado.
De modo geral, os escravos estavam sujeitos a condições de higiene precárias em suas habitações, a ritmo intenso de trabalho, dieta carente de nutrientes e falta de repouso para recuperar as energias. Corpos mal alimentados e trabalhando em excesso tornavam-se alvo fácil de doenças, principalmente das infecto-parasíticas, como a tuberculose ou de problemas no aparelho digestivo, como as gastrites. Este mesmo quadro já foi apontado para outras regiões do Brasil, conforme mostraram Mary Karasch (2000) e Thiago dos Reis (2007) para o Rio de Janeiro da primeira e segunda metade do século XIX, respectivamente.

É preciso considerar também que o diagnóstico muitas vezes era impreciso, como no caso da "febre meningo gástrica" e o tratamento das doenças inadequado. Apesar de que muitos escravos recebiam tratamento no hospital da própria SCMP, os mais velhos e doentes, tidos como "inválidos e inutilizados", eram levados para a fazenda Graciosa, no rio Capim, onde esperavam a hora da morte. Um indicativo das condições de moradia dos escravos da fazenda Graciosa é a observação do Dr. Francisco da Silva Castro, que esteve pessoalmente na fazenda em 1863: "os ranchos dos escravos também carecem de pequenas obras, que as mandei fazer" (SCM 1863:12). O provedor contabiliza na Graciosa 40 escravos, sendo 15 crianças de um a sete anos de ambos os sexos, e 25 maiores, sendo 11 homens e 13 mulheres. Destes, porém, só 13 trabalhavam no campo. Concluiu o Dr. Silva Castro que "os mais, uns 
trabalham pouco, porque estão meio velhos, e adoentados, outros nada trabalham, porque estão inteiramente velhos e gastos". Se a situação dos ranchos dos escravos chamou a atenção do provedor, nada é dito sobre a necessidade de cuidar da saúde dos que estavam "meio velhos, e adoentados" ou "inteiramente velhos e gastos". Como vimos mais acima, Silva Castro definia a Graciosa como excelente retiro para velhos, aposentados ou reformados, além de "viveiro" para as crianças.

Além de funcionar como correção para escravos "viciosos" e abrigo para os que eram considerados "velhos e gastos", a fazenda Graciosa, ao que indica a documentação, acabou por adquirir ao longo dos anos outra função estratégica. Aos cinco de outubro de 1863, o provedor Dr. Francisco da Silva Castro dizia em seu relatório que, dos oito escravos que foram internados na "enfermaria para alienados", criada "para guardar os loucos furiosos", dentro do Hospital de Caridade "três foram mandados para a fazenda Graciosa, da Santa Casa, no rio Capim, para tomarem banhos, arejarem e distraírem-se com o serviço do campo em companhia dos escravos da Santa Casa ali existentes" (SCM 1863: 6-7). De acordo com os estudos neurofisiológicos típicos da época, estes indivíduos descontrolados, em função do desequilíbrio do sistema nervoso, poderiam colocar em risco a própria vida em sociedade. Disso resultava a necessidade de isolá-los, variando o destino dos homens e mulheres "nervosos" de acordo com o grau atribuído à sua doença (Harris 1993). A referência aos banhos que os escravos tomariam na fazenda Graciosa também fazia parte dos procedimentos utilizados na época e que tinham na hidroterapia importante aliado no re-equilíbrio das funções "nervosas" dos indivíduos (Marras 2004). A fazenda Graciosa era o purgatório dos escravos da Santa Casa de Misericórdia do Pará.

\section{À GUISA DE CONCLUSÃO}

Segundo Vianna (1992: 276), a partir de 1860, a SCMP vendeu vários de seus escravos e não comprou mais nenhum. Aos três de abril de 1867, período em que a irmandade possuía 92 escravos, decidiu-se oferecer ao presidente $\mathrm{da}$ província os escravos que estivessem em condições de serem alistados nas fileiras do exército brasileiro para marcharem para a guerra do Paraguai (1864-1870). Segundo o provedor interino, Candido do Prado Pinto, vários escravos se apresentaram voluntariamente, sendo que 13 deles foram aceitos pelo presidente da província, que indenizou a SCMP em 14:300\$000 rs. (SCM 1868:4). Motivados pelas promessas de liberdade feitas àqueles que defendessem o Império brasileiro no conflito com os paraguaios, os escravos da SCMP partiram numa aventura cujo final desconhecemos, mas que possivelmente para muitos não teve retorno. Somaram-se aos muitos outros escravos de diversas partes do país, que contribuíram para a "mudança na coloração" do exército brasileiro, recebendo dos paraguaios a alcunha pejorativa de "los macaquitos" (Schwarcz 2003:306). 
Em 1880, no fervor da agitação abolicionista e oito anos antes da Lei Áurea, a Santa Casa alforriou os nove últimos escravos que possuía. Não por vontade própria, mas por determinação de José Coelho da Gama e Abreu, presidente da Província, que negou o pedido de indenização feito pela irmandade. Determinava a lei $\mathrm{n}^{\circ} 1.026$, de 2 de maio de 1880: "No I" dia do anno compromissal d'esta lei ficarão livres todos os escravos da Santa casa, sem onus algum para elles" (Vianna 1992:276). Muito embora contrariada pela recusa ao pedido de indenização, a mesa diretora da irmandade não abriu mão de explorar simbolicamente aquela situação. Quatro dias depois, "reuniu-se a Meza em sessão, fez comparecer os escravos e entregou-lhes as cartas de alforria, completamente legalisadas" (Vianna 1992:277). Salles refere que o "espontaneísmo de certas libertações será, no Pará, como nas demais províncias, tremendamente espalhafatoso, com nome dos magnânimos doadores nos jornais, etc." (1988:280). Talvez por isso os administradores da SCMP se preocupassem em reunir os escravos em sessão extraordinária, com vistas a colher os frutos simbólicos de uma manumissão que, se nada tinha de espontânea, poderia render a simpatia dos escravos alforriados e dos adeptos do abolicionismo.

O presidente da província divulgou a notícia de que a SCMP não possuía mais nenhum escravo, em 1881 , no tópico do relatório referente aos cemitérios. Dizia o presidente:
"Cemitérios.

Dispondo a lei do orçamento vigente que do $1^{\circ}$ de julho em diante seriam considerados livres os escravos da Santa Casa, mas, tendo esta proposto à presidência que se esperasse pela reunião da assembléia provincial, para ser realizada esta medida, solicitando o ser indenizada da parte que perdia do valor de seu patrimônio com aquela manumissão, indeferi esta proposta, mantendo a disposição da lei, e hoje não possui a Santa Casa escravo algum.” (Pará 1881:63-64)

A relação da Santa Casa com seus escravos aponta para a diversidade de experiências vividas por senhores e escravos e também ajuda a pensar a importância da questão étnica como um elemento fundamental para a configuração das irmandades, donde surgem confrarias de pretos, de brancos e até mesmo de índios (Figueiredo \& Henrique 1997). Se para os escravos a experiência na Santa Casa era difícil, deve-se enfatizar que as ações da Misericórdia eram comuns àquela época e que o trabalho assistencial da irmandade muito aliviou o sofrimento dos doentes, indigentes, condenados à morte ou presidiários, muitas vezes escravos. Conforme observou Charles Boxer, "enquanto a caridade de que a Misericórdia se ocupava estendia-se amplamente aos pobres e necessitados, as outras irmandades, laicas ou confrarias das várias ordens religiosas, em geral restringiam suas atividades caritativas a seus próprios membros e suas famílias" (2002:305). Bastante significativas, neste sentido, são as palavras do Dr. Silva Castro, ao afirmar 
que no Hospital Bom Jesus dos Pobres, no largo da Sé,

"são recolhidos todos os doentes de ambos os sexos, que o procuram, sem distinção de cor, nacionalidade, ou religião e nele se exercita a caridade, como a recomenda o nosso Divino Mestre e a ciência de Hipócrates.

Também nele se recebem pensionistas escravos, ou livres, que careçam dos socorros da medicina. $\mathrm{O}$ acesso para o hospital é franco e livre de dependências; as suas portas estão sempre abertas para a pobreza necessitada, sem ser preciso licença do provedor ou do respectivo mordomo. O regente tem ordem de recolher tudo quanto verdadeiramente tiver cara de doente e de pobre. São estas as duas únicas condições que se requerem para o impetrante auferir o direito de entrada" (SCM 1863: 235)

Dentre as medidas adotadas pelo provedor Mathias José da Silva Cunha (1837-1838) para superar as dificuldades da SCMP no período da Cabanagem, Vianna (1992:146) cita a cobrança junto aos senhores de uma quantia para assistência dos escravos com elefantíase. O custo com a internação de escravos no hospital era de responsabilidade dos senhores, mas estes nem sempre cumpriam com suas obrigações. Em momentos críticos da história do Pará no século XIX, seja na Cabanagem, nas epidemias de cólera, febre amarela ou varíola, a Santa Casa de Misericórdia cumpriu importante papel de prestar auxílio médico aos mais diversos segmentos da sociedade paraense, fossem eles abonados ou "desvalidos da sorte". Da mesma forma, aliviava as apreensões na hora da morte, haja vista o pavor que se tinha de uma morte súbita, sem preparação e mais ainda o temor de ser enterrado sem funeral e sepultura adequados. Conforme observou Vianna (1992:258), era comum a crença de que a alma não entrava no céu enquanto o corpo estivesse insepulto ou enterrado em campo aberto. O serviço funerário prestado pela SCMP diminuía o pavor dos devotos, principalmente os mais pobres e os escravos que não contavam com a proteção de nenhuma irmandade, de terem para sempre cerradas as portas do paraíso.

Sem dúvida, a SCMP é uma das mais importantes instituições da Amazônia, estando ligada a muitos fatos históri$\cos$ da região e sendo responsável por várias instâncias do atendimento médico na região. Até o início do século XX, era ela quem administrava o chamado Hospício dos Lázaros do Tucunduba, transformado em abrigo para os hansenianos desde 1814 , no local onde existiu antiga olaria antes pertencente aos religiosos mercedários. Em 1874, data de abertura do cemitério de Santa Isabel, para receber as vítimas da epidemia de varíola, também foi reservada à SCMP a sua administração. Os enterramentos no Cemitério da Soledade foram suspensos em 1880. Ainda no século XIX, a SCMP marcou presença junto aos migrantes nordestinos que, sonhando em melhorar de vida nos seringais da Amazônia, foram flagelados pela varíola. 
Em 1890, o Governador Justo Chermont assinou decreto dando novo estatuto à SCMP, que deixou de ser Irmandade e passou a ser Associação Civil de Caridade. Na mesma data, foi lançada a primeira pedra do novo Hospital da Caridade, no bairro do Umarizal. Também em 1890, decreto republicano determinou a secularização dos cemitérios, em função do que a SCMP entregou a administração dos cemitérios da Soledade e de Santa Isabel à Intendência Municipal. Para a SCMP isto representou enorme prejuízo, por fechar-lhe importante fonte de rendas e desfalcar-lhe o patrimônio.

Em 1892, a SCMP passou a administrar o Hospício dos Alienados (depois Hospital Juliano Moreira, na atual av. Almirante Barroso). Anos depois passou a administrar também o Hospital de Isolamento, depois chamado Hospital Domingos Freire, construído para o recolhimento de doentes com moléstias infecto-contagiosas, situado à rua Barão de Mamoré com Mundurucús, onde hoje se encontra o Hospital Barros Barreto. Escravos, indigentes, "alienados", pobres, hansenianos, "desvalidos da sorte" ou "homens abonados", todos faziam uso, de alguma forma, dos serviços prestados pela secular Santa Casa de Misericórdia do Pará.

No século XIX, ruas, rios e praças eram palco de múltiplas experiências para os escravos, espaços ambíguos e conflitantes onde eles poderiam experimentar do açoite ao batuque, da forca à coroa. Felizmente para os escravos, havia a possibilidade de se organizar em suas próprias irmandades, o que eles fizeram nas mais diferentes paragens do Pará oitocentista.
Cite-se, como exemplo, a Irmandade do Glorioso São Benedito, organizada por escravos em lugares como Belém, Bragança, Cintra (atual Maracanã), Gurupá e São Caetano de Odivelas, a de Nossa Senhora do Livramento da cidade de Santarém, a de Nossa Senhora do Rosário dos Pretos da Campina ou a de São Raimundo Nonato, ambas em Belém. Certamente que muitos dos escravos da SCMP participaram destas associações. Mas esta já é outra história (Henrique 1997).

\section{NOTAS}

${ }^{1}$ Para atuar dentro da legalidade, as Irmandades precisavam ter seus Compromissos aprovados em instâncias civil e religiosa, obedecendo as prerrogativas do regime de Padroado vigente no Brasil. Na instância civil, os Compromissos eram aprovados pelo presidente da província a partir de uma autorização que lhe foi conferida pela Assembléia Legislativa Provincial, em 1842. Mas antes da confirmação do presidente da província, os compromissos deveriam ser analisados e confirmados pelo bispo diocesano. No século XVIII, os compromissos deveriam ser enviados para Lisboa, onde seriam confirmados pelo Tribunal da Mesa de Consciência e Ordens (Cf. Scarano 1975:22)

${ }^{2}$ Estatutos da Associação de Caridade Santa Casa da Misericórdia. Pará Typ. de A Província do Pará, 1891, p. II.

${ }^{3}$ Em 1849, no governo provincial de Jerônymo Coelho, adotou-se um novo Compromisso para a Santa Casa de Misericórdia do Pará, a partir do qual se intensificou a subordinação da irmandade aos poderes públicos da Província. Até então, vigorava o Compromisso de 1618 (Vianna 1992: 155). Para uma interessante discussão das manifestações do 
preconceito religioso e racial no Brasil, conferir Carneiro 1988.

${ }^{4}$ Cf. Estatutos da Associação de Caridade Santa Casa da Misericórdia. Pará Typ. de $A$ Província do Pará, 1891, pp. 11-17.

${ }^{5} \mathrm{O}$ primeiro prédio da Santa Casa de Misericórdia do Pará situava-se no Largo das Mercês, no local onde atualmente se encontra a loja Paris N'América. Em 1807, todos os bens do Hospital Bom Jesus dos Pobres, construído por Frei Caetano Brandão no Largo da Sé, foram incorporados à Santa Casa, que funcionou nesse local entre 1807 e 1900. O Hospital Bom Jesus dos Pobres foi demolido na segunda metade do século XX e ficava onde hoje se encontra um chafariz ao lado da Casa das Onž Janelas, espaço de entretenimento em Belém. Somente em 1900 a SCMP passou a funcionar no prédio atual, situado à rua Oliveira Belo, bairro do Umarizal.

${ }^{6}$ Essas religiosas prestaram serviços na SCMP até o início da década de 1990, quando a instituição tornou-se fundação ligada ao governo do Estado do Pará.

${ }^{7}$ Sobre a epidemia de cólera no Pará, ver Beltrão 2004.

${ }^{8}$ Em fevereiro de 1851, o escravo conhecido como pai Antonio foi enforcado na praça da matriz de Santarém, por ter sido acusado de assassinar seu feitor, que tentou obrigá-lo a trabalhar, embora fosse sexagenário e estivesse doente. Detalhe curioso deste episódio, é que o carrasco de Santarém, Domingos Pixuna, era antigo cabano que aceitou essa "profissão" como forma de livrar-se da morte (Campos 1977:39-41). Se é verdade que na vila do Tapajós (hoje Santarém), o elemento predominante na Cabanagem (1835-1840) foi o índio e o caboclo, permanecendo os negros escravos geralmente fiéis aos seus senhores (Santos 1986:24) e contribuindo na perseguição aos cabanos, neste episódio os papéis se inverteram, tendo-se um ex-cabano atuando como carrasco de um escravo.

\section{REFERÊNCIAS}

Beltrão, J. 2004. Cólera, o flagelo da Belém do Grão-Pará. Belém: Museu Paraense Emílio Goeldi; Universidade Federal do Pará.

Bezerra-Neto, J.M. 2001. Escravidão negra no Grão-Pará (sécs. XV II-XIX). Belém: Paka Tatu.

Boxer, C. 2002. O império marítimo português (14251825). São Paulo: Companhia das Letras.

Campos, J.V. G. 1977. A última execução capital no Pará. Revista do Instituto Histórico e Geográfico do Pará I(1):39-41.

Carneiro, M. L.T. 1988. Preconceito racial: Portugal e Brasil-Colônia. São Paulo: Brasiliense.

Carrara, S. 1996. Tributo a Vênus. A luta contra a sífilis no Brasil, da passagem do século aos anos 40. Rio de Janeiro: Editora Fiocruz.

Chernoviz, P. L. N. 1878. Diccionario de Medicina Popular e das Sciencias Accessorias. Vol. I. Paris: em casa do autor. $5^{\text {a }}$ edição.

Cruz, E. s/d. Belém: aspectos geo-sociais do município. Belém: Livraria José Olympio Editora.

Figueiredo, A. M. de \& M.C. Henrique. 1997. Os Devotos do Vimioso: uma confraria de índios no Pará do século XIX. Cadernos de História Social 5: 71-77.

Harris, R. 1993. Assassinato e loucura: medicina, leis e sociedade no fin de siècle. Rio de Janeiro: Rocco.

Henrique, M. C. 1997. O Senbor do Céu não éo Senhor da Terra: a experiência religiosa dos escravos nas Irmandades paraenses (1839-1889). Monografia de Conclusão de Curso de Graduação. Departamento de História, Universidade Federal do Pará, Belém.Inédito.

Karasch, M. C. 2000. A vida dos escravos no Rio de Janeiro (1808-1850). São Paulo: Companhia das Letras.

Marras, S. A. 2004. A propósito de águas virtuosas. Belo Horizonte: UFMG. 
Reis, J. J. 1991. A morte é uma festa: ritos fúnebres e revolta popular no Brasil do século XIX. São Paulo: Companhia das Letras.

Reis, T. de S. dos. 2007. Livro de Óbitos de Captivos da Freguesia de Nossa Senhora da Conceição de Vassouras: um estudo demográfico, 1865-1888. Monografia de Conclusão de Curso de Graduação. Departamento de História, Universidade Federal do Estado do Rio de Janeiro, Rio de Janeiro. Inédito.

Salles, V. 1988. O Negro no Pará. $2^{\mathrm{a}}$ ed. Belém: Secult.

Santos, J. 1986. Cabanagem em Santarém. Santarém: Livraria Ática.

Scarano, J. 1975. Devoção e Escravidão: a Irmandade de Nossa Senhora do Rosário dos Pretos no Distrito Diamantino no Século XVIII. São Paulo: Cia. Ed. Nacional.

Schwarcz, L.M. 2003. As barbas do Imperador: D. Pedro II, um monarca nos trópicos. São Paulo: Cia. das Letras.

Silva, E. 1989. Entre Zumbi e Pai João: o escravo que negocia, in Negociação e conflito: a resistência negra no Brasil escravista. Editado por J. J. Reis \& E. Silva, pp. 13-21. São Paulo: Cia. das Letras.

Stedman, T. L. 1996. Dicionário Médico. Rio de Janeiro: ed. Guanabara Koogan.

Vergolino-Henry, A. \& A. N. Figueiredo. 1990. A presença africana na Amazônia Colonial: uma notícia histórica. Belém: Arquivo Público do Pará.

Vianna, A. 1992. A Santa Casa da Misericórdia Paraense: notícia bistórica (1650-1902). Belém: SECULT.

Zarur, D. C.. 1981. A Santa Casa na história: fonte de lu₹, caridade e justiça. Rio de Janeiro: S/E.

\section{Fontes Documentais}

Estatutos da Associação de Caridade Santa Casa da Misericórdia. 1891. Pará: Typ. de A Província do Pará.

PARÁ, Governo. 1838. Discurso com que o presidente da província do Pará fez a abertura da $1^{a}$ sessão da Assembléa Provincial no dia 2 de março de 1838. Pará: Typographia Restaurada de Santos e Santos Menor.

PARÁ, Governo. 1844. Discurso recitado pelo Exmo. Snr. Desembargador Manoel Paranhos da Silva Vellozo, Presidente da Província do Pará, na abertura da primeira Sessão da Quarta Legislatura da Assembléa Provincial, no dia 15 de agosto de 1844. Pará, Typographia de Santos \& Menores.

PARÁ, Governo. 1845. Discurso recitado pelo Exmo. Snr. Doutor João Maria de Moraes, vice-presidente da província do Pará, na abertura da Segunda Sessão da Quarta Legislatura da Assembléa Provincial, no dia 15 de agosto de 1845. Pará, Typographia de Santos \& Filhos.

PARÁ, Governo. 1847. Discurso recitado pelo Exmo. Sr. Dr. José Maria de Moraes, vice-presidente da Província do Pará, na abertura da segunda sessão da quinta legislatura da Assembléa Provincial. Pará: Typographia de Santos \& Filhos.

PARÁ, Governo. 1849. Fala dirigida pelo Exmo. Snr. Conselheiro Jerônimo Francisco Coelho, presidente da província do Gram-Pará, à Assembléa Legislativa Provincial, na abertura da segunda sessão ordinária da sexta legislatura, no dia $1^{\circ}$ de outubro de 1849. Pará: Typographia de Santos e Filhos.

PARÁ, Governo. 1852. Relatório apresentado ao Exmo. Snr. Dr. José Joaquim da Cunha, presidente da Província do Gram-Pará pelo Comendador Fausto Augusto de Aguiar por ocasião de entregar-lhe a administração da 
Província no dia 20 de agosto de 1852. Pará, Typographia de Santos \& Filhos.

PARÁ, Governo. 1861. Relatório dirigido a Assemblea Legislativa da Província do Pará na Segunda Sessão da XII Legislatura pelo Exm. Sr. Dr. Francisco Carlos de Araújo Brusque, Presidente da mesma Província, em 17 de agosto de 1861. Pará, Typographia do Diário do Gram-Pará.

PARÁ, Governo. 1863. Relatório apresentado a Assemblea Legislativa da Província do Pará na Segunda Sessão da XIII Legislatura pelo Excellentissimo Senhor Presidente da Província Doutor Francisco Carlos de Araújo Brusque, em $1^{\circ}$ de novembro de 1863. Pará, Typographia de Frederico Carlos Rhossard.

PARÁ, Governo. 1881. Relatório apresentado à Assembléa Legislativa Provincial na $2^{\mathrm{a}}$ Sessão da $22^{\mathrm{a}}$ Legislatura, em 15 de fevereiro de 1881, pelo Exmo. Sr. Dr. José Coelho da Gama e Abreu. Pará, Typ. do Diário de Noticias, de Costa \& Campbell.

SCM. 1863. Relatório da Santa Caza da Mizericordia. Belém, Secretaria da Santa Caza da Mizericordia do Pará, 5 de outubro.

SCM. 1868. Relatório da Santa Caza da Mizericordia. Belém, Secretaria da Santa Caza da Mizericordia do Pará, 9 de junho.

Recebido em 15/01/2013.

Aprovado em 20/03/2013. 